\title{
The Prevalence and Determinants of Preference of Long Term Contraceptive Methods among Married Women in Arba Minch Town, Ethiopia
}

\author{
Tariku Tesfaye Haile, Belay Belete Anjullo \\ Department of Statistics, Arba Minch University, Arba Minch, Ethiopia \\ Email address: \\ tariku.tesfaye@amu.edu.et (T. T. Haile), belay.belete@amu.edu.et (B. B. Anjullo)
}

\section{To cite this article:}

Tariku Tesfaye Haile, Belay Belete Anjullo. The Prevalence and Determinants of Preference of Long Term Contraceptive Methods among Married Women in Arba Minch Town, Ethiopia. International Journal of Biomedical Materials Research. Vol. 6, No. 2, 2018 , pp. $26-34$. doi: $10.11648 /$ j.ijbmr.20180602.11

Received: June 18, 2018; Accepted: July 4, 2018; Published: July 27, 2018

\begin{abstract}
Ethiopia is one of the sub-Saharan African countries with alarming population growth rate and high total fertility rate. To reduce high population growth and high fertility, the usage of modern contraceptive methods which classified as short term and long term methods is crucial among women. Despite widespread adoption of family planning in the developing world, the usage of modern contraceptive methods and preference of long term method is still relatively very low in subSaharan Africa including Ethiopia. Hence, the general objective of this study was assessing the prevalence of modern contraceptive methods and identifying the potential factors influencing the preferences of long term contraceptive methods among married women of reproductive age (15-49) in Arba Minch town. Community based cross sectional study design was employed. A single stage simple random sampling was used as sampling technique and sample of 990 women was determined using a formula for estimation of single population proportion. Descriptive analysis was employed to estimate the prevalence and potential predictors were selected by using chi-square test of association between preference of the modern contraceptive methods and predictors. Those predictors that showed p-value less than or equal to 0.25 were taken to binary logistic regression analysis to identify the determinants. From a descriptive analysis, out of 990 sampled married women about $57.9 \%$ (573) were modern contraception methods users. Among these 573 modern contraceptive method users, 147 (27.73\%) were long term methods users, like injectable, implant and intrauterine devices. From binary logistic regression analysis, age of the respondent, religion of women, number of children in a family, education level of women, desire for more child, experience on modern contraceptive use, frequency of watching television, availability of service in nearby place and service provider were found to be statistically significant predictors of preference of long term contraceptive methods among married women of reproductive age in Arba Minch town.
\end{abstract}

Keywords: Binary Logistic Regression, Modern Contraceptive Methods, Long Term Contraceptive Method, Married Women of Reproductive Age

\section{Introduction}

\subsection{Background}

Ethiopia is one of the sub-Saharan African countries with alarming population growth rate and high total fertility rate. To reduce high population growth and high fertility, the usage of modern contraceptive methods which classified as short term and long term methods is crucial among women. Long term contraceptives methods (LTCMs) are contraceptive methods that prevent unwanted pregnancy and spacing options for at least three years and when removed return of fertility is prompt. This are modern contraceptive methods which have low failure rate, safer and cost effective than short term contraceptives and this includes implant and Intrauterine devices [1].

Long-term and permanent methods (LTPMs) are safe and effective protection against pregnancy for those who wants to benefit from access to contraceptive choices. These are by far the most effective (>99\%) methods of contraception 
available and are very safe and convenient. The long term nature of these forms of contraception does not require daily motivation on the part of users and thus have higher continuation and effectiveness rates. Couples also require fewer visits to health providers, thus saving time, effort and money, and the patient load at health care facilities is lessened. This means that they are cost effective for programs over time. At a system level, the use of LTPMs can result in substantial cost savings for governments, and contribute directly to reaching national and international health goals. Other indirect advantages are the reduction of high maternal mortality and morbidity, as well as elective abortions. According to a study done in different nations across the globe, more than 300,000 abortions per year in Vietnam, more than 100,000 in Ukraine, and 80,000 in Turkey could be averted by the use of LTPMs [2].

Despite these advantages, LTPMs remain a relatively small, and sometimes missing, component of many national reproductive health and family planning programs. Strong family planning programs offer a full range of contraceptive methods, but in many places, LTPMs are the least available, the least used, and possibly the least understood methods by clients $[1,3]$. Approximately $25 \%$ of women and couples in sub-Saharan Africa who wants to space or limit their births are not using any form of contraception [4]. Over time, the use of long term contraceptives has not kept pace with that of short-term methods, such as oral contraceptives and injectable. Data from demographic and health surveys from four sub-Saharan African countries show that the proportion of women currently using long term contraceptives is significantly lower than the proportion using short-term methods. In many countries in the region, fewer than $5 \%$ of women who are using contraception are using long term contraceptives [5].

The Ethiopia Federal Ministry of Health (FMoH) has considered the important role of LTPMs and aims to increase the availability of these methods to $20 \%$ of all family planning clients. Use of family planning in Ethiopia has traditionally focused on short-term methods such as injectable and birth control pills. LTPMs accounted for only $4 \%$ of users in 2011 in Ethiopia [6]. It was reported that long term contraceptive methods are safe, effective and convenient methods of preventing unplanned and unwanted pregnancy [7-9].

However, according to Ethiopia Demographic and Health Survey (EDHS) 2011 report the contribution of long term contraceptives for contraceptive prevalence rate was very low. Similarly, the same report showed that, there was $9 \%$ unmet need for limiting. However, which factors contribute to the low utilization and higher unmet needs of these methods locally and nationally are not well studied. In addition, there was no such a study that assessed the determinants of long term contraceptive at the study area [1012]. Therefore, this study aimed to assess the prevalence of modern contraceptive methods and identifying the determinants of preference of the long term contraceptive methods utilization among married women of reproductive age groups at Arba Minch town, Gamo Gofa zone, Ethiopia.

\subsection{Statement of the Problem}

Many studies indicated the benefits of contraceptive use are dramatic and far-reaching. Some of the benefits of contraceptive use are decreasing fertility rate, preventing unintended pregnancies, reducing the number of abortions, and reducing the incidence of deaths and illnesses related to complications of pregnancy and childbirth. Despite the overall high knowledge of women about modern contraceptive methods, contraceptive use is relatively low in Ethiopia. According to the data from EDHS 2010, awareness of women in reproductive ages of at least one modern contraceptive method is as high as 88 percent, whereas for currently married accounts it is 87 percent. The current use of modern contraceptives is only 14 percent among married women which are totally dominated by short term methods such as pill compared to long term methods such as injectable intrauterine device (IUD) and implants and only 0.3 and 0.2 percent of women gave unavailability and high price, respectively as the reason for not using contraception [13]. It was also reported that, long term contraceptive methods are safe, effective and convenient methods of preventing unplanned and unwanted pregnancy (10-15). Therefore studying the barriers to use long term contraceptive methods is a top priority action to improve its utilization. Hence, this study was attempted to answer the following research questions.

1. What was the prevalence of modern contraceptive methods usage among married women of reproductive age?

2. What was prevalence of long term contraceptive method usage among married women of reproductive age?

3. What were the potential factors influencing the preferences of long term contraceptive methods among married women of reproductive age?

\subsection{Objectives of the Study}

The main objective of this study was to estimate the prevalence of modern contraceptive methods and identify factors influencing the preferences of long term contraceptive methods utility among married women of reproductive age (15-49 years) in Arba Minch Town, Sothern region, Ethiopia.

\section{Methodology}

\subsection{Study Area and Population}

The study was conducted in Arba Minch town which is found in Gamo Gofa zone in southern nation's nationalities and people's regional state (SNNPRS). It is situated at 505 $\mathrm{km}$ to south of Addis Ababa. According to Central Statistical Agency in 2007 population and housing census, the population size of Arba Minch town was 74, 843 residing in four sub city administrations namely Sikela, Secha, Abaya and Nech Sar. The target population for the study was all 
married women in the child bearing age (15-49) in Arba Minch town.

\subsection{Study Design and Method of Data Collection}

A cross-sectional study design was employed among married women of reproductive age in Arba Minch town, SNNPR, Ethiopia. Before data collection, training was given to all enumerators on how they collect data based on the design of the study. Primary data was collected using face-toface interview by structured questionnaire guided interview on status of family planning utilization. The questions were prepared in English version and translated to Amharic. The community leaders were used for familiarizing the area for data collectors and support during data collection process. Whole data collection process was coordinated and supervised by principal investigators.

\subsection{Sampling Techniques and Sample Size Determination}

A single stage simple random sampling method was adopted as sampling method to select household from study area. Finally, eligible women of reproductive age in the selected households were asked to participate in the study. When two or more married women were in a household, only one of them was randomly asked to participate, to avoid intra-class correlation. A sample size of 990 was determined using a formula in (1) for estimation of single population proportion [14] with the assumption of 5\% Type I error, 3\% margin of error, and $47 \%$ prevalence of modern contraceptive method usage from pilot study conducted in the study area. Sample size $n=990$ was determined as shown below:

$$
\mathrm{n}=\frac{\mathrm{NZ}^{2} \frac{\alpha}{2} \mathrm{PQ}}{\mathrm{Nd}^{2}+\mathrm{Z}^{2} \frac{\alpha}{2} \mathrm{PQ}}=\frac{14261 *(1.96)^{2} * 0.47 * 0.53}{14261 *(0.03)^{2}+(1.96)^{2} * 0.47 * 0.53}=989.69 \approx 990
$$

Where, $\mathrm{N}$ is total number of married women in child bearing age at Arba Minch town, $\mathrm{P}$ is proportion of women who used modern contraceptive methods, $\mathrm{Q}$ is proportion of women who did not use modern contraceptive methods, d margin error, $Z \alpha / 2$ is tabulated value from standard normal table at $5 \%$ level of significance.

\subsection{Variables Considered in the Study}

\section{Dependent Variable}

The dependent variable used in this study was contraceptive method preference categorized as short term and long term method and coded as 1 if preference is long term contraceptive method and 0 if preference is short term contraceptive method.

Independent Variables

The independent variables included in the study were factors that are expected to influence long term contraceptive method preferences among married women of reproductive ages (15-49). The variables are age of the respondent, religion of the respondent, husband's education level, number of children, education level of wife, desire for more child, husband's occupation, husband's monthly income, family planning field workers visit, frequency of watching television, source of information, number of known method types, experience on modern contraceptive use frequency of following radio program, availability of service in near place, husband's encouragement, and service provider.

$$
\log \operatorname{it}\left(P_{i}\right)=\log \left(\frac{P_{i}}{1-P_{i}}\right)=\beta_{o}+\beta_{1} X_{i 1}+\beta_{2} X_{i 2}+\ldots+\beta_{p} X_{i p}
$$

Where, $\mathrm{P}_{\mathrm{i}}=$ the probability that the $\mathrm{i}^{\text {th }}$ woman preference to be long term contraceptive method, $\mathrm{Y}_{\mathrm{i}}=$ the observed method preference status of the $\mathrm{i}^{\text {th }}$ woman, $X_{1}, X_{2}, \ldots, X_{p}$ are set of independent variables and $\beta_{0}, \beta_{1}, \ldots, \beta_{\mathrm{p}}$ are coefficient of unknown regression parameters estimated by using maximum likelihood estimation method [16]. The

\subsection{Method of Data Analysis}

Binary Logistic Regression Model

The linear regression model is, under certain conditions, a valuable tool for quantifying the effects of several explanatory variables on one dependent continuous variable. For situations where the dependent variable is qualitative, however, other methods have been developed. One of these is the binary logistic regression model, where the dependent or response variable is dichotomous (binary), such as presence or absence of an attribute (success or failure) [15]. It assumes that the dependent or outcome variable $\mathrm{Y}$ is dichotomous and value of the outcome variable $Y_{i}(i=1,2 \ldots, n)$ follows a Bernoulli distribution, that is, $\mathrm{Y}_{\mathrm{i}}$ takes either the value 1 with probability of success $P_{i}$, and the value 0 with probability of failure $1-\mathrm{P}_{i}$, where $\mathrm{P}_{\mathrm{i}}$ represents the conditional probability of $\mathrm{Y}_{\mathrm{i}}=1$ given the explanatory variables, that is $\mathrm{P}_{\mathrm{i}}=\mathrm{P}\left(\mathrm{Y}_{\mathrm{i}}\right.$ $=1 \mid \mathrm{X})$ and $\mathrm{X}=\left(X_{1}, X_{2}, \ldots, X_{p}\right)$. The dependent variable considered in the study was dichotomous as 1 if preference is long term contraceptive method and 0 if preference is short term contraceptive method. Thus, to examine the net effect of the predictors on the response variables, that is method preference (short-term $=0$, long-term $=1$ ), binary logistic regression analysis method was used. For binary response variable $\mathrm{Y}$, multiple binary logistic regression model with logit link function has the form given in equation (2): overall goodness of fit of the model was also tested. The Pearson's Chi-square, the likelihood ratio tests (LRT), Hosmer and Lemeshow Test and the Wald tests are the most commonly used measures of goodness of fit for categorical data [17] and they were used in this study. 


\section{Results}

Data were entered, cleaned and explored for outliers, missed values and any inconsistencies and then analyzed using SPSS version 16. Descriptive analysis was done via frequency and percentage to determine the prevalence of modern contraceptive methods and preference of long term methods. Then, associations between dependent and independent variables were evaluated using chi-square test, the results were presented using p-value in two way table. Those independent variables that showed p-values less than or equal to 0.25 were taken to multiple binary logistic regression analysis as results are depicted subsequently.

\subsection{Descriptive Analysis}

The data used for the study were obtained from 990 married women of reproductive age (15-49) in Arba Minch town. From result in Table 1, out of 990 married women of reproductive age included in the study, about $57.9 \%$ (573) were using one of the modern contraceptive methods, while $42.1 \%(417)$ were not using any modern contraceptive methods.

Among 573 modern contraceptive users, 426 (74.3\%) were short term users whereas $147(25.7 \%)$ were long term methods users. Of 426 short term users, 350 (82.2\%) were pill users, $61(14.3 \%)$ were lactational amenorrea users and $15(3.5 \%)$ were condom users. Among 147 long term users, $138(93.9 \%)$ were injectable users, $6(4.1 \%)$ were implant users, and $3(2 \%)$ were intrauterine devices users.

Table 1. Counts and Percentages of Married Women Who Used Modern Contraceptive Methods and Method Preferences for Random Sample of 990 (Arba Minch Town, 2015).

\begin{tabular}{|c|c|c|}
\hline Characteristics & \multirow{2}{*}{ Count } & \multirow{2}{*}{ Percent (\%) } \\
\hline Modern contraceptive usage & & \\
\hline User & 573 & 57.9 \\
\hline Non user & 417 & 42.1 \\
\hline \multicolumn{3}{|l|}{ Method Preference } \\
\hline Short term methods user & 426 & 74.3 \\
\hline Pill & 350 & 82.2 \\
\hline Lactational Amenorrea & 61 & 14.3 \\
\hline Long term methods user & 147 & 25.7 \\
\hline Injectables & 138 & 93.9 \\
\hline Implant & 6 & 4.1 \\
\hline Intrauterine Devices & 3 & 2 \\
\hline
\end{tabular}

\subsection{Cross Tabulation and Chi-Square Test of Association}

The association between the response variables (method preference) and the predictor variables was examined using chi-square test. Table 2 shows results of cross tabulation between methods preference and potential predictors, and chi-square test of association. From cross tabulation, it was observed that, out of 573 modern contraceptive users in the age group of $25-34,45$ (7.9\%) were long term users whereas short term users accounts $31.1 \%$ (178). While in the age category of $35-44,89(15.5 \%)$ were long term users and 40 $(7 \%)$ were short term users. This indicates that the usage of long term contraceptive methods seemed to be higher in the age group of 35-44.

Regarding the educational status of interviewed married women, $12(2.1 \%)$ were long term contraceptive methods users could not be able to read and write, 69 (12\%) were educated college/university or higher and used long term contraceptive methods. This shows that educational status of mothers appeared to be potential predictor for the utility of modern contraceptive methods as an increasing trend was observed.

Regarding the number of children, the percentage of women with no children, $1-2,3-4$ and $>=5$ children that were currently using long term modern contraception methods were $8(1.4 \%), 14(2.4 \%), 45(7.9 \%)$ and $80(14.0 \%)$, respectively. This implies that long term modern contraceptive usage among women becomes higher as the numbers of children increases. Similarly, for the educational level of husband with college/university diploma or higher the usage of long term and short term contraceptive methods for their wives were $59(10.3 \%)$ and $160 \quad(27.7 \%)$ respectively. However, husband who could not write and read utility of long term and short term contraceptive methods for their wives were $3(0.5 \%)$ and $9(1.6 \%)$, respectively.

The percentages of long term modern contraceptive method usage with regard to availability of nearby service, $118(20.6 \%)$ were getting the service from nearby location and $29(5.1 \%)$ were not. This implies that those who were getting the service nearby had better chance to use long term modern contraception method. Moreover, the percent of long term contraceptive method usage according to the service provider shows that; hospital, health center, clinic, and family planning service provider were $5(0.9 \%), 58(10.1 \%), 16$ $(2.8 \%)$ and $68(11.9 \%)$ respectively. This result shows that, long term contraceptive usage was higher among women who were getting service from family planning service provider. From chi-square test of association it can be seen that the age of women, religion of women, number of children in a family, desire for more child, education level of women, education level of husband, occupation of women, monthly income of women, husbands occupation, monthly income husband, frequency of watching television, source of information, experience on the usage of modern contraceptive method, availability of service near place and 
source of service provider were potential predictors of preference of long term contraceptive method at $25 \%$ level of significance. Those predictors were incorporated in multiple binary logistic regressions to identify the determinants of preference of long term contraceptive methods.

Table 2. Cross Tabulation And Chi-Square Test of Association Between Method Preferences and Predictor Variables for 573 Married Women (Arba Minch Town, 2015).

\begin{tabular}{|c|c|c|c|c|}
\hline \multirow{2}{*}{ Variables } & \multirow{2}{*}{ Categories } & \multicolumn{2}{|l|}{ Method preference } & \multirow{2}{*}{ Chi-square (P-value) } \\
\hline & & Long term Count (\%) & Short term Count (\%) & \\
\hline \multirow{3}{*}{ Age of Respondent } & $15-24$ & $13(2.3)$ & $208(36.3)$ & \multirow{3}{*}{$6.435(0.04)^{*}$} \\
\hline & $25-34$ & $45(7.9)$ & $178(31.1)$ & \\
\hline & $35-44$ & $89(15.5)$ & $40(7.0)$ & \\
\hline \multirow{4}{*}{ Religion of Respondent } & Orthodox & $87(15.2)$ & $210(36.6)$ & \multirow{4}{*}{$14.715(0.002)^{*}$} \\
\hline & Muslim & $16(2.8)$ & $21(3.7)$ & \\
\hline & Protestant & $40(7.0)$ & $180(31.4)$ & \\
\hline & Other & $4(0.7)$ & $15(2.6)$ & \\
\hline \multirow{4}{*}{ Number of children } & No child & $8(1.4)$ & $36(6.3)$ & \multirow{4}{*}{$10.112(0.018)^{*}$} \\
\hline & $1-2$ children & $14(2.4)$ & $270(47.1)$ & \\
\hline & 3 - 4 children & $45(7.9)$ & $102(17.8)$ & \\
\hline & $>=5$ children & $80(14.0)$ & $18(3.1)$ & \\
\hline \multirow{2}{*}{ Desire for more child } & No & $107(18.7)$ & $264(46.1)$ & \multirow{2}{*}{$5.603(0.018)^{*}$} \\
\hline & Yes & $40(7.0)$ & $162(28.3)$ & \\
\hline \multirow{4}{*}{ Wife's education level } & Illiterate & $12(2.1)$ & $37(6.5)$ & \multirow{4}{*}{$7.084(0.069)^{*}$} \\
\hline & Primary & $19(3.3)$ & $67(11.7)$ & \\
\hline & Secondary & $47(8.2)$ & $141(24.6)$ & \\
\hline & College/university diploma or higher & $69(12.0)$ & $181(31.6)$ & \\
\hline \multirow{6}{*}{ Wife's Occupation } & House wife & $95(16.6)$ & $238(41.5)$ & \multirow{6}{*}{$9.174(0.057)^{*}$} \\
\hline & Government employee & $9(1.6)$ & $50(8.7)$ & \\
\hline & Day laborer & $1(0.2)$ & $18(3.1)$ & \\
\hline & Owen business & $31(5.4)$ & $93(16.2)$ & \\
\hline & Private organization & $11(1.9)$ & $27(4.7)$ & \\
\hline & None & $79(13.8)$ & $216(37.7)$ & \\
\hline & Illiterate & $3(0.5)$ & $9(1.6)$ & \\
\hline & Primary & $26(4.5)$ & $127(22.2)$ & \\
\hline Husband's education level & Secondary & $59(10.3)$ & $130(22.7)$ & $9.276(0.026)^{*}$ \\
\hline & College/university diploma or higher & $59(10.3)$ & $160(27.7)$ & \\
\hline & $100-400$ & $8(1.4)$ & $68(11.9)$ & \\
\hline & $400-700$ & $26(4.5)$ & $64(11.2)$ & \\
\hline Wife's Monthly income & $700-1000$ & $29(5.1)$ & $53(9.2)$ & $15.134(0.004)^{*}$ \\
\hline & $>=1000$ & $5(0.9)$ & $25(83.3)$ & \\
\hline & None & $8(1.4)$ & $5(0.9)$ & \\
\hline & Government employee & $54(9.4)$ & $160(27.7)$ & \\
\hline Husband's Occupation & Day laborer & $11(1.9)$ & $69(12.0)$ & $17.134(0.002)^{*}$ \\
\hline & Owen business & $51(8.9)$ & $116(20.2)$ & \\
\hline & Private organization & $23(4.0)$ & $76(13.3)$ & \\
\hline & $100-400$ & $14(2.4)$ & $61(10.6)$ & \\
\hline & $400-700$ & $21(3.7)$ & $92(16.1)$ & \\
\hline Husband's IMonthly income & $700-1000$ & $37(6.5)$ & $102(17.6)$ & $1.963(0.04 /)^{4}$ \\
\hline & $>=1000$ & $75(13.1)$ & $171(29.8)$ & \\
\hline Family planning field workers visit & Yes & $90(15.7)$ & $264(46.1)$ & $0026(0.872)$ \\
\hline Family planning tield workers visit & No & $57(9.9)$ & $162(28.3)$ & $0.026(0.8 / 2)$ \\
\hline & Almost every day & $39(6.8)$ & $128(22.3)$ & \\
\hline Frequency of following radio & Occasionally & $82(14.3)$ & $206(36.0)$ & $2475(0.480)$ \\
\hline program & At least once a week & $12(2.1)$ & $42(7.3)$ & $2.4 / 5(0.480)$ \\
\hline & Not at all & $14(2.4)$ & $50(8.7)$ & \\
\hline & Almost every day & $73(12.7)$ & $207(36.1)$ & \\
\hline Frequency of following television & Occasionally & $73(12.7)$ & $207(36.1)$ & $10844(0013)$ \\
\hline program & At least once a week & $7(1.2)$ & $58(10.1)$ & $10.844(0.013)^{*}$ \\
\hline & Not at all & $4(0.7)$ & $18(3.1)$ & \\
\hline & Media & $49(8.6)$ & $162(28.3)$ & \\
\hline & Health center & $53(9.2)$ & $181(31.6)$ & \\
\hline Source of information & Friends & $19(3.3)$ & $36(6.3)$ & $7.840(0.049)^{*}$ \\
\hline & Family planning field workers visit & $26(4.5)$ & $47(8.2)$ & \\
\hline & $1-3$ & $56(9.8)$ & $184(32.1)$ & \\
\hline Number of known methods & $>=4$ & $91(15.9)$ & $242(42.2)$ & $1.16 /(0.280)$ \\
\hline Experience on modern & Yes & $300(52.4)$ & $211(36.8)$ & \\
\hline Contraceptive use & No & $43(7.5)$ & $18(3.1)$ & $3.15(0.0 / 0)^{*}$ \\
\hline Husband's encouragement & Yes & $129(22.8)$ & $387(67.5)$ & $1.165(0.280)$ \\
\hline
\end{tabular}




\begin{tabular}{|c|c|c|c|c|}
\hline \multirow{3}{*}{ Variables } & \multirow{2}{*}{ Categories } & \multicolumn{2}{|l|}{ Method preference } & \multirow{2}{*}{ Chi-square (P-value) } \\
\hline & & Long term Count (\%) & Short term Count (\%) & \\
\hline & No & $18(3.1)$ & $39(6.8)$ & \multirow{3}{*}{$4.047(0.044)^{*}$} \\
\hline \multirow{2}{*}{$\begin{array}{l}\text { Availability of Service in near } \\
\text { place }\end{array}$} & Yes & $118(20.6)$ & $306(53.4)$ & \\
\hline & $\begin{array}{l}\text { No } \\
\text { Hospital }\end{array}$ & $\begin{array}{l}29(5.1) \\
5(0.9)\end{array}$ & $\begin{array}{l}120(20.9) \\
9(1.6)\end{array}$ & \\
\hline \multirow{3}{*}{ Service provider } & Health center & $58(10.1)$ & $248(43.3)$ & \multirow{3}{*}{$16.652(0.001)^{*}$} \\
\hline & Clinic & $16(2.8)$ & $24(4.2)$ & \\
\hline & Family planning service provider & $68(11.9)$ & $145(25.3)$ & \\
\hline
\end{tabular}

$*=\mathrm{p}$-valve $<0.25$ indicates potential predictors for binary logistic regression analysis

\subsection{Binary Logistic Regression Analysis}

Binary logistic regression analysis was performed to explore the effect of socio-economic and demographic factors on the long term contraceptive method preference among married women. All the variables involved in the analysis were categorical and variables from chi-square test of association (Table 2) with p-value $<0.25$ were fitted to the model. Those in multiple binary logistic regression analysis with $\mathrm{p}$-value $<0.05$ for at least one category were maintained and reported. Thus, to interpret the results of the analysis, the first category of the variables was taken as reference category for this study.

As illustrated in Table 3, age of women, religion of respondents, number of children in a family, desire for more children, education level of women, frequency of watching television, experience of women on the usage of modern contraceptive methods, availability of service nearby place from their resident and service provider were found to be statistically significant predictors of long term contraceptive method preference.

Married women whose age was between 25-34 and 35-44 were 2.612 and 3.323 times more likely to use long term contraceptive method than those in age group 15-24. Regarding women's religion, followers of other than protestant and Muslim religions were 4.949 times more likely to use long term contraceptive methods than those women who follow orthodox religion. Likewise, women whose number of children is between $1-2,3-4$ and $>=5$ were 4.82 , 8.529 and 24.01, time more likely to use long term contraceptive methods than women with no child, respectively. This implies that long term methods usage increases as the number of children increases in a family. Moreover, women who had desire for additional children were 0.459 times less likely to use long term methods than their counter part.

Similarly, it was found that, women's education level was one of statistically significant predictor of long term contraceptive method preference. Mothers with education level of secondary school and College/University diploma or higher were 3.916 and 4.87 times more likely to use long term contraceptive method than those who can read and write, respectively. Frequency of watching television had significant contribution in promoting utilization of long term contraceptive methods. Women who watch television occasionally, at least once a week and did not watch at all were $87.1 \%, 87.8 \%$ and $94.5 \%$ less likely to use long term contraceptive methods compared to those who watch television almost every day, respectively.

Concerning experience on the usage of modern contraceptive methods, it was also one of the significant predictors of long term contraceptive methods utility. Women who had experience on the usage of modern contraceptive methods were 2.95 times more likely to utilize long term contraceptive methods compared to those who had no experience on the usage of modern contraceptive methods.

Similarly, availability of services nearby place had statistically significant effect on the usage long term contraceptive methods; hence, for those women the availability of services was not nearby place, the utility of long term contraceptive methods was $54.8 \%$ less likely as compared to those who had services nearby place. It was also found that a service provider was a significant predictor for utility of long term contraceptive methods. Women who had had services from family planning service providers were 2 times more likely to use long term contraceptive methods compared to those women who had got services from hospital.

Table 3. Parameters Estimation of Binary Logistic Regression Model (Arba Minch Town, 2015).

\begin{tabular}{|c|c|c|c|c|c|c|c|c|c|}
\hline \multirow{2}{*}{ Predictors } & \multirow{2}{*}{ Categories } & \multirow{2}{*}{$\widehat{\boldsymbol{\beta}}$} & \multirow{2}{*}{ S. E $(\widehat{\boldsymbol{\beta}})$} & \multirow{2}{*}{ Wald } & \multirow{2}{*}{ df } & \multirow{2}{*}{ p-value } & \multirow{2}{*}{$\operatorname{Exp}(\widehat{\boldsymbol{\beta}})$} & \multicolumn{2}{|c|}{$95 \%$ C. I for $\operatorname{Exp}(\widehat{\beta})$} \\
\hline & & & & & & & & Lower & \\
\hline \multirow{3}{*}{ Age group } & $15-24$ (Ref) & & & 8.195 & 2 & 0.017 & & & \\
\hline & $25-34$ & 0.960 & 0.223 & 18.532 & 1 & $<0.0001^{*}$ & 2.612 & 1.687 & 4.043 \\
\hline & $35-44$ & 1.201 & 0.516 & 5.424 & 1 & $0.020^{*}$ & 3.323 & 1.209 & 9.137 \\
\hline \multirow{4}{*}{ Religion of respondent } & Orthodox (Ref) & & & 11.962 & 3 & $0.008^{*}$ & & & \\
\hline & Muslim & 0.915 & 0.791 & 1.336 & 1 & 0.248 & 2.496 & 0.529 & 11.78 \\
\hline & Protestant & 0.028 & 0.921 & 0.001 & 1 & 0.975 & 1.029 & 0.169 & 6.251 \\
\hline & Others & 1.599 & 0.797 & 4.025 & 1 & $0.045^{*}$ & 4.949 & 1.037 & 23.61 \\
\hline \multirow{4}{*}{ Number of Children } & No Child (Ref) & & & 15.132 & 3 & $0.002^{*}$ & & & \\
\hline & 1-2 Children & 1.574 & 0.588 & 7.152 & 1 & $0.007^{*}$ & 4.825 & 1.522 & 15.29 \\
\hline & 3-4 Children & 2.143 & 0.606 & 12.509 & 1 & $0.000^{*}$ & 8.529 & 2.600 & 27.97 \\
\hline & $>4$ Children & 3.178 & 0.905 & 12.321 & 1 & $0.000^{*}$ & 24.01 & 4.070 & 141.6 \\
\hline
\end{tabular}




\begin{tabular}{|c|c|c|c|c|c|c|c|c|c|}
\hline \multirow{2}{*}{ Predictors } & \multirow{2}{*}{ Categories } & \multirow{2}{*}{$\widehat{\boldsymbol{\beta}}$} & \multirow{2}{*}{ S. E $(\widehat{\boldsymbol{\beta}})$} & \multirow{2}{*}{ Wald } & \multirow{2}{*}{ df } & \multirow{2}{*}{ p-value } & \multirow{2}{*}{$\operatorname{Exp}(\widehat{\beta})$} & \multicolumn{2}{|c|}{$95 \%$ C. I for $\operatorname{Exp}(\widehat{\beta})$} \\
\hline & & & & & & & & Lower & \\
\hline \multirow{2}{*}{ Desire for More Child } & No (Ref) & & & & & & & & \\
\hline & Yes & -0.778 & 0.338 & 5.291 & 1 & $0.021^{*}$ & 0.459 & 0.237 & 0.891 \\
\hline \multirow{5}{*}{ Education level of Wives } & Illiterate (Ref) & & & 13.032 & 3 & $0.005^{*}$ & & & \\
\hline & Primary & 0.304 & 0.521 & 0.341 & 1 & 0.559 & 1.355 & 0.488 & 3.763 \\
\hline & Secondary & 1.365 & 0.559 & 5.956 & 1 & $0.015^{*}$ & 3.916 & 1.309 & 11.712 \\
\hline & College/University diploma or Higher & 1.583 & 0.742 & 4.547 & 1 & $0.033^{*}$ & 4.870 & 1.137 & 20.840 \\
\hline & Almost Every Day (Ref) & & & 11.781 & 3 & $0.008^{*}$ & & & \\
\hline Frequency of Watching & Occasionally & -2.047 & 0.626 & 10.703 & 1 & $0.001^{*}$ & 0.129 & 0.038 & 0.440 \\
\hline \multirow[t]{2}{*}{ Television } & At least once a week & -2.104 & 0.628 & 11.225 & 1 & $0.001^{*}$ & 0.122 & 0.036 & 0.418 \\
\hline & Not at all & -2.890 & 0.882 & 10.736 & 1 & $0.001^{*}$ & 0.055 & 0.010 & 0.313 \\
\hline Experience on Modern & No (Ref) & & & & & & & & \\
\hline Contraceptive Methods & Yes & 1.082 & 0.471 & 5.267 & 1 & $0.022^{*}$ & 2.950 & 1.171 & 7.433 \\
\hline Availability of Services & Yes (Ref) & & & & & & & & \\
\hline nearby place & No & -0.793 & 0.373 & 4.514 & 1 & $0.034^{*}$ & 0.452 & 0.218 & 0.940 \\
\hline \multirow{4}{*}{ Service Provider } & Hospital (Ref) & & & 13.617 & 3 & $0.003^{*}$ & & & \\
\hline & Health Center & -1.377 & 0.971 & 2.010 & 1 & 0.156 & 0.252 & 0.038 & 1.693 \\
\hline & Clinic & -0.591 & 0.559 & 1.118 & 1 & 0.290 & 0.554 & 0.185 & 1.656 \\
\hline & Family Planning Service Providers & 0.697 & 0.289 & 5.800 & 1 & $0.016^{*}$ & 2.008 & 1.139 & 3.539 \\
\hline Constant & & 0.014 & 1.472 & 0.000 & 1 & 0.992 & 1.014 & & \\
\hline
\end{tabular}

Ref $=$ Reference category, S. E = standard error, $*=$ p-valve $<5 \%$ level of significance indicates significant predictor

\section{Discussion}

This study was conducted in attempting to assess the usage of modern contraceptive method and identifying the determinant factors affecting the preference of long term contraceptive method among married women of reproductive ages (15-49) in Arba Minch town.

As the result revealed, out of 990 married women of reproductive ages included in the study, about $57.9 \%$ (573) were using one of the modern contraception methods, while $42.1 \%$ (417) were not using any modern contraception methods. In a study conducted in Mojo town, the prevalence of modern contraceptive utilization was $38.3 \%$ [18] and this figure was lower compared to finding in this study. Regarding preference of modern contraceptive methods, among 573 modern contraceptive users, 426 (74.3\%) women were preferred short term methods, whereas about 147 (25.7\%) women were long term users like injectable, implant and intrauterine devices users. This finding is nearly in line with the evidence from a study conducted on long-Acting reversible contraceptive methods (LARM) among married women of reproductive age group in Adaba town (30.3\%) and Western Ethiopia $(20 \%)[19,20]$. However, the finding of this study was higher as compared with the study in Mekelle (12\%), report of EDHS 2011 and national based estimates $6.1 \%$ of women use LARM as reported in Ethiopia mini DHS, (2014) [21-23] and lower as compared to the results of the study conducted in Adigrat town (37\%) [24]. This might be due to difference in the socioeconomic status and individual factors of the married women.

In this study, age of women had a statistically significant effect on long term contraceptive method preference. It was observed that there was increasing trend on the preference of long term contraceptive methods with increment of age category as compared to age category of 15-24. This is similar with a study conducted in Adaba town and at national level $[19,25]$. The educational status of women was also found to be an important predictor of long term contraceptive method preference. As women's education level increases, the preference of long term contraceptive method increases among married women. This agrees with studies done in Adaba, Western Ethiopia and Durame $[19,20,26]$. The possible explanation could be that better educated women would likely have access for information on modern contraceptive methods and their increased knowledge on modern contraceptives. This might be due to the fact that educational status of women influence service use and decision-making power on reproductive health care issues particularly family planning.

In addition, the frequency of watching television was statistically significant in predicting preference of long term contraceptive methods, where women who were following television program frequently were more likely to prefer long term method as compared to those who did not watch television. This study concord with the study conducted in western Ethiopia, Durame and Indonesia [20, 26, 27]. This finding was surprise as reports showed, exposure to information on television and radio can increase knowledge and awareness of new ideas, social changes, and opportunities and can affect an individual's perceptions and behavior, including those about health [27]. Regarding family planning service providers, it was also found to be one of the influential factors on preference of long term contraceptive methods. Those women who obtained modern contraceptive service from family planning service providers were more likely to prefer long term methods than those women from hospitals, health centers and clinics. Similar results were obtained from the studies conducted in Hosanna [28]. The reason might be inadequate discussion between health professionals with customer on reproductive health issues especially on long term contraceptive method due to work overload in governmental health facilities.

Moreover, number of children in a family was found to be another significant factor in determining the preference of 
long term contraceptive methods, where women who had no child were less likely to prefer long term contraceptive methods than those who had one or more children. This result is in line with the result of research done in France from multivariable analysis of trends and barriers of longActing reversible contraceptive methods. It was revealed that, women who had more than two children were more likely to use long-acting reversible contraceptive methods than women who had no child [29]. This may be due to women who have children may reach their preferred family size. Therefore, these women were more likely to control pregnancy by using more effective methods. Finally, experience on using of modern contraceptive method was found to be determinant of utilizing long term contraceptive methods, where experienced women were more likely to use long term contraceptive method than those never used it. The result of this finding was in line with the study conducted in Durame, Southern Ethiopia and Mana district, Jimma zone $[26,30]$.

\section{Conclusions and Recommendations}

The main purpose of this study was to estimate the prevalence of the usage of modern contraceptive methods and identifying the determinant factors affecting preference of long term contraceptive methods among married women of reproductive ages (15-49) in Arba Minch Town.

In general, this study revealed the prevalence of modern contraceptive methods usage among married women of reproductive age was $57.9 \%$ and there was a low utilization of long term contraceptive methods $(25.7 \%)$ compared to short term contraceptive methods $(74.3 \%)$ in the study area. From multiple binary logistic regression analysis, it was found that, age of the respondent, religion of women, number of children in a family, education level of women, desire for more child, experience on modern contraceptive use, frequency of watching television, availability of service in nearby place and service provider for women were statistically significant predictors of preference of long term contraceptive methods among married women of reproductive age. Hence, empowering women through formal education, encourage women to have habit of vising hospitals and health centers for family planning, providing services for women in nearby place, encouraging women to watch television frequently and enhance experience of the utilizing modern contraceptive methods were highly recommended.

\section{Acknowledgements}

The authors thank the Arba Minch University for providing necessary facilities for research work and for financial support. Our sincere gratitude also goes $\mathrm{Mr}$. Wondiber Nega from Arba Minch University, Statistics department, Arba Minch, Ethiopia for his initial contribution, to all supervisors, data collectors and study participants for their cooperation and support during the study period.
Finally, we would like to thank mayor of Arba Minch town for his encourage and support to conduct this study.

\section{Funding}

This research was fully funded by Arba Minch University, community service and research directorate.

\section{Availability of Data and Materials}

The dataset supporting conclusions of this article is available by contacting authors.

\section{Disclaimers}

The authors are solely responsible for the research and the findings do not represent the opinions or endorsement of any of the funders.

\section{Authors' Contributions}

BBA and TTH designed the study, analyzed the data drafted the manuscript and critically reviewed the article. All authors read and approved the final manuscript.

\section{Ethical Considerations}

The study was carried out after getting permission from the ethical clearance committee of College of Natural Sciences, Arba Minch University. After Ethical clearance and approval of the University Ethical Committee and up on the permission of local government administration bodies of the town, the actual research activities was undertaken in the study area.

\section{Competing Interests}

The authors declare that they have no competing interests.

\section{Consent for Publication}

Not applicable.

\section{References}

[1] USAID: United States Agency for International Development. Using Quantification to Support Introduction and Expansion of Long-Acting and Permanent Methods of Contraception. 2010. http://www.respondproject.org/archive/files/3/3.3/Using-Quantification-toSupport.pdf Accessed October 2010.

[2] Bradley SEK, Croft TN, Rutstein SO. The impact of contraceptive failure on unintended births and induced abortions: Estimates and Strategies for Reduction, in DHS analytical studies 22. ICF Macro: Calverton, Maryland, USA; 2011. https://dhsprogram.com/pubs/pdf/AS22/AS22.pdf. Accessed September 2011. 
[3] Nancy Y, Stella B. Factors underlying the use of long-acting and permanent methods of contraception (LA/PMS) in Cambodia, Malawi and Nigeria. Qualitative Study. USAID, Respond Project. 2011. http://www.respondproject.org/archive/files/4/4.1/4.1.3/Study5-2012-FactorsUnderlining.pdf.

[4] USAIDS/FHI. Addressing unmet need for family planning in Africa: The case for long-acting and permanent methods. 2007.

[5] Janowitz B, Gmach R, Otterness C. The commercial sector's role in providing long-acting and permanent methods. Private Sector Partnerships-One Project/Abt Associates Inc. 2006. http://pdf.usaid.gov/pdf_docs/Pnadh604.pdf. Accessed August 2006.

[6] Central Statistical Agency Ethiopia and ORC Macro Ethiopia Demographic and Health Survey. Addis Ababa, Ethiopia and Calverton, Maryland. USA: Central Statistical Agency and ORC Macro; 2011. p. 93-99.

https://dhsprogram.com/pubs/pdf/FR255/FR255.pdf. Accessed March 2012.

[7] WHO, UNICEF, UNFPA and The World Bank. Trends in maternal mortality: 1990-2010. World Health Organization: Geneva; 2012.

http://www.who.int/reproductivehealth/publications/monitorin g/9789241503631/en/.

[8] Maggwa N. The case for long acting and permanent methods. United States Agency for International Development (USAID) FHI; 2008.

[9] Acquiring Knowledge Project. Acquiring knowledge by applying lessons learned to strengthen FP/RH services. Acquire project: New York; 2008.

[10] Blumenthal P, Shah N, Jain K, Saunders A, Clements C. Revitalizing long-acting reversible contraceptives in settings with high unmet need: a multicounty experience matching demand creation and service delivery. Contraception. 2012; $87: 170-175$.

[11] Kavanaugh ML, Jerman J, Hubacher D, Kosk K, Finer L. Characteristics of women in the United States who use Long acting Reversible Contraceptive methods. Obstet Gynecol. 2011; 117: 1349-1357.

[12] United States Agency for International Development. Longacting and permanent methods of contraception: Meeting Clients' Needs. Issue Brief Washington, DC: USAID; 2006.

[13] Central Statistical Agency Ethiopia and ORC Macro Ethiopia Demographic and Health Survey (2010). Addis Ababa, Ethiopia and Calverton, Maryland. USA: Central Statistical Agency and ORC Macro; 2011. p. 41-91.

[14] Cochran WG. Sampling Techniques. 3rd Edition. John Wiley \& Sons Inc: New York; 1977.

[15] Agresti A. Categorical Data Analysis. John Wiley \& Sons, Inc; 2002.

[16] Hosmer D, Cessie S, Lemeshow S. A Comparison of Goodness-of-fit: Tests for The Logistic Regression Model. Epidemiology, University of Massachusetts: Arnold House; 1989.
[17] Hosmer D, Lemeshow S. Applied Logistic Regression (2nd Edition). New York: John Wiley and Sons; 2000.

[18] Abebe G, Nigatu R. Family planning service utilization in Mojo town, Ethiopia: A population based study. Journal of Geography and Regional Planning. 2011; 4 (6):355-363.

[19] Fekadu H, Kumera A, Yesuf EA, Hussien G, Tafa M. Prevalence and Determinant Factors of Long Acting Contraceptive Utilization among Married Women of Reproductive Age in Adaba Town, West Arsi Zone, Oromia, Ethiopia. J Women's Health Care. 2017; 6:60. doi:10.4172/2167-0420.1000360.

[20] Alemu SM, Tesfalidet T, Desalegn W. Determinants of long acting and permanent contraceptive methods utilization among married women of reproductive age groups in western Ethiopia: A cross-sectional study. Pan African Medical Journal. 2015. ISSN: 1937- 8688.

[21] Alemayehu M, Belachew T, Tilahun T. Factors associated with utilization of long acting and permanent contraceptive methods among married women of reproductive age in Mekelle town, Tigray region, North Ethiopia. 2012; 12: 6.

[22] Central Statistical Agency Ethiopia and ORC Macro Ethiopia Demographic and Health Survey (2011). Addis Ababa, Ethiopia and Calverton, Maryland. USA: Central Statistical Agency and ORC Macro. 2012; p. 93-99.

[23] Central Statistical Agency, Ethiopia. Ethiopia Mini Demographic and Health Survey, Addis Ababa; 2014.

[24] Gebreyesus B, Berhe S, Bayray A. Assessment of long acting and permanent contraceptive method utilization and associated factors among married women of reproductive age group in Adigrat town, Tigray region, Ethiopia. 2015; 2:36-45.

[25] Alemayehu S, Abebach A. Determinants of long acting contraceptive use among reproductive age women in Ethiopia: Evidence from EDHS 2011. Science Journal of Public Health. 2015; 3 (1):143-149.

[26] Yirgaw ET, Ewenat G, Mesele DA. Determinants of Long Acting Reversible Contraceptive Method Use among Mothers in Extended Postpartum Period, Durame Town, Southern Ethiopia: Across Sectional Community Based Survey. Scientific Research Publishing: Health. 2015; 7:1315-1326.

[27] Rahayu R, Utomo I, McDonald P. Contraceptive Use Pattern among Married Women in Indonesia; the International Conference on Family Planning; Uganda. Research and Best Practices. 2009; 15-18.

[28] Alemu E, Abebaw G, and Teresa K. Determinants of Long Acting and Permanent Contraceptive Methods Utilization among Married Women in Hossana Town, Southern Ethiopia: A Case-Control Study. J Preg Child Health. 2015; 2:3.

[29] Moreau C, Bohet A, Mireille Le G, Bajos N. Trends and barriers of use of long acting reversible contraception in France: Results from a population based survey. 2012.

[30] Dibab Y. Child Spacing and Fertility Planning Behavior among Women in Mana District, Jimma Zone, South West Ethiopia. Ethiopian Journal of Health Science. 2010; 20:8390 . 